\title{
Etched FBG written in multimode fibers: sensing characteristics and applications in the liquid fuels sector
}

\author{
Raquel de Paiva Corotti, Juliana Thaler, Hypolito José Kalinowski, Marcia Muller, José Luís Fabris \\ and Ricardo Canute Kamikawachi \\ Federal University of Technology - Paraná, 80230-901, Curitiba, Brazil \\ E-mail address: canute@utfpr.edu.br (R.C.Kamikawachi)
}

\begin{abstract}
In this work, a refractometric fiber sensor for the liquid fuels sector is described. The use of etched FBGs produced in multimode fibers is proposed to overcome the drawbacks associated with sensing high refractive index samples employing fiber transducers. The transducer sensitivity can be tailored by adjusting the final diameter of the etched Bragg grating. Due to a trade-off between the signal-to-noise ratio and the sensitivity, operational parameters of the sensor must be designed to match the expected refractive index dynamic range for specific applications. Metrological properties of the sensor are determined, resulting in resolution from $5.6 \% \mathrm{v} / \mathrm{v}$ to $0.4 \% \mathrm{v} / \mathrm{v}$ for refractive indexes ranging from 1.4562 to 1.4729 . Specific applications regarding the quality assessment of biodiesel and conformity analysis of dieselbiodiesel blends are discussed.
\end{abstract}

Index Terms-Optical fiber transducer, chemical sensor, refractometric sensor, biodiesel analysis.

\section{INTRODUCTION}

In recent years, the Brazilian government has increased incentives for the research and development of renewable energy sources. Within this scenario, biodiesel plays an important role, as biofuel can either be incorporated as part of or even replace diesel - the liquid fuel most produced, commercialized and consumed in Brazil [1, 2]. Besides the renewability, biodiesel combustion brings less impact to the environment than the use of other fossil fuels. From 2005 on, the addition of biodiesel to diesel was mandatory and the biodiesel percentage in biodiesel-diesel blend has been increased in the long run [3]. According to the Brazilian law number 13.033/2014, biodiesel percentage in biodiesel-diesel blend commercialized in Brazil must reach $7 \%$ until the end of 2014, and in the following years it is expected to reach an upper limit of $27.5 \%$. As a new technology, its production as well as quality and conformity monitoring still presents few methods and instruments to assess standards, for both production and commercialization sectors [4 - 6].

The biodiesel is produced by a chemical reaction known as transesterification, with the conversion of a fatty acid into an ester and generating glycerin as a by-product. Some authors [7, 8] showed that it is possible to monitor the ester conversion by the determination of the sample refractive index. Such possibility instigated studies about the performance of optical fiber devices as long period gratings 
(LPG) and LPG based interferometers to analyze biodiesel and biodiesel-diesel blends quality and conformity, not only along the production but also during the commercialization stage [8 - 10]. Operation of this kind of sensor relies on the measurement of the sample refractive index, which may indicate both the presence of remaining products from the transesterification reaction in biodiesel samples and the percentage of biodiesel in biodiesel-diesel blend. However, an important setback for the application of this sensing technology is the effective refractive index of the optical fiber cladding. When the measurand is more refractive than the fiber cladding, LPG shows low sensitivity and the interferometric transducer stops working properly. This limitation compromises the analysis of biodiesel and biodiesel-diesel blends which refractive indexes are equal to or higher than the fiber cladding one.

As attempts to work out such drawbacks, approaches taking advantage of samples thermo-optic coefficients, employing the addition of low refractive index solvents to the sample or providing partial immersion of the transducer, have been proposed [9]. An alternative solution not yet explored is the use of cladding-less optical fiber transducers, as the core refractive index is higher than the fiber cladding one. Such approach could make possible sensing samples more refractive than the cladding of such fibers. In a recent work, Tsigaridas et al [11] showed the effective refractive index of a wet etched single-mode fiber becomes more affected by the refractive index of the external medium as the fiber radius decreases. This increase in the sensitivity is more noticeable when the etching process evolves beyond the cladding-core boundary, however at expense of the fiber integrity and the light guiding capability. Shivananju et al [12] showed that etched Fiber Bragg Gratings (FBG) could be more effective than SPR (Surface Plasmon Resonance) based techniques, provided the etching process is developed until the final fiber radius is $2 \mu \mathrm{m}$ or less.

In this work, we propose the development and application of a fiber optic refractometric sensor based on etched multimode instead of single-mode fiber, assuring the sensor operation without the need for an auxiliary approach to guarantee the fiber integrity. The transducer comprises an etched FBG written in a multimode fiber. Metrological characteristics of the proposed sensor are demonstrated for application in the field of liquid fuels.

\section{Methodology}

Bragg gratings were written in multimode fiber (50 $\mu \mathrm{m}$ core, $125 \mu \mathrm{m}$ cladding diameters) with an excimer ArF laser (Coherent Xantos XS, at $193 \mathrm{~nm}$ ) by direct exposition through a phase mask $(1075.5 \mu \mathrm{m}$ pitch). Wet etching was employed to reduce the diameter of the fiber containing the FBG. Cladding was gradually corroded by immersing the fiber in a hydrofluoric acid solution at $40 \%$. After reached the desired diameter, etching process was stopped by the subsequent immersion of the fiber in a $\mathrm{NaOH}$ solution. FBGs were interrogated by an optical spectrum analyzer (OSA - Yokogawa AQ6375, \pm 5 pm of wavelength stability), by using an ASE as optical source and an optical circulator connecting the devices. The etched FBGs had its final diameters determined by scanning electron 
microscopy (SEM - EVO MA 15, Carl Zeiss Microscopy).

For determining the etched-FBGs response curves and sensitivities to the external medium refractive index at a temperature of $(22.0 \pm 1.0){ }^{\circ} \mathrm{C}$, the device was immersed in samples containing different proportions of water and glycerin. Glycerin concentration in samples ranged from $0.0 \%$ to $100.0 \%$ in steps of $10.0 \%$ and uncertainty of $0.1 \% \mathrm{v} / \mathrm{v}$. In order to study the sensor ability to quantify the presence of remaining vegetable oil in biodiesel, the device response curve was also obtained in the presence of samples containing soybean oil and biodiesel in different proportions. Concentrations of oil in the samples ranged from $0.0 \%$ to $100.0 \%$ in steps of $10.0 \%$ and $0.1 \% \mathrm{v} / \mathrm{v}$ of uncertainty. Grating response curve results from five measurements done under reproducibility conditions. Samples refractive indexes were measured with an Abbe refractometer (Atago DR-A1, 0.5 x $10^{-4}$ resolution operating at sodium D line $543.5 \mathrm{~nm}$ ).

\section{RESULTS AND DISCUSSIONS}

Figures 1 (a), (b) and (c) show images obtained with SEM for three produced etched FBGs with final diameters of $32 \mu \mathrm{m}, 12 \mu \mathrm{m}$ and $7 \mu \mathrm{m}$. Figure 1 (d) shows FBG reflection spectrum for fiber with diameter of $32 \mu \mathrm{m}$, when the sample containing $0.00 \%$ of glycerin and $100.00 \%$ of water $(1.3328$ refractive index at $22.0^{\circ} \mathrm{C}$ ) is the external medium.
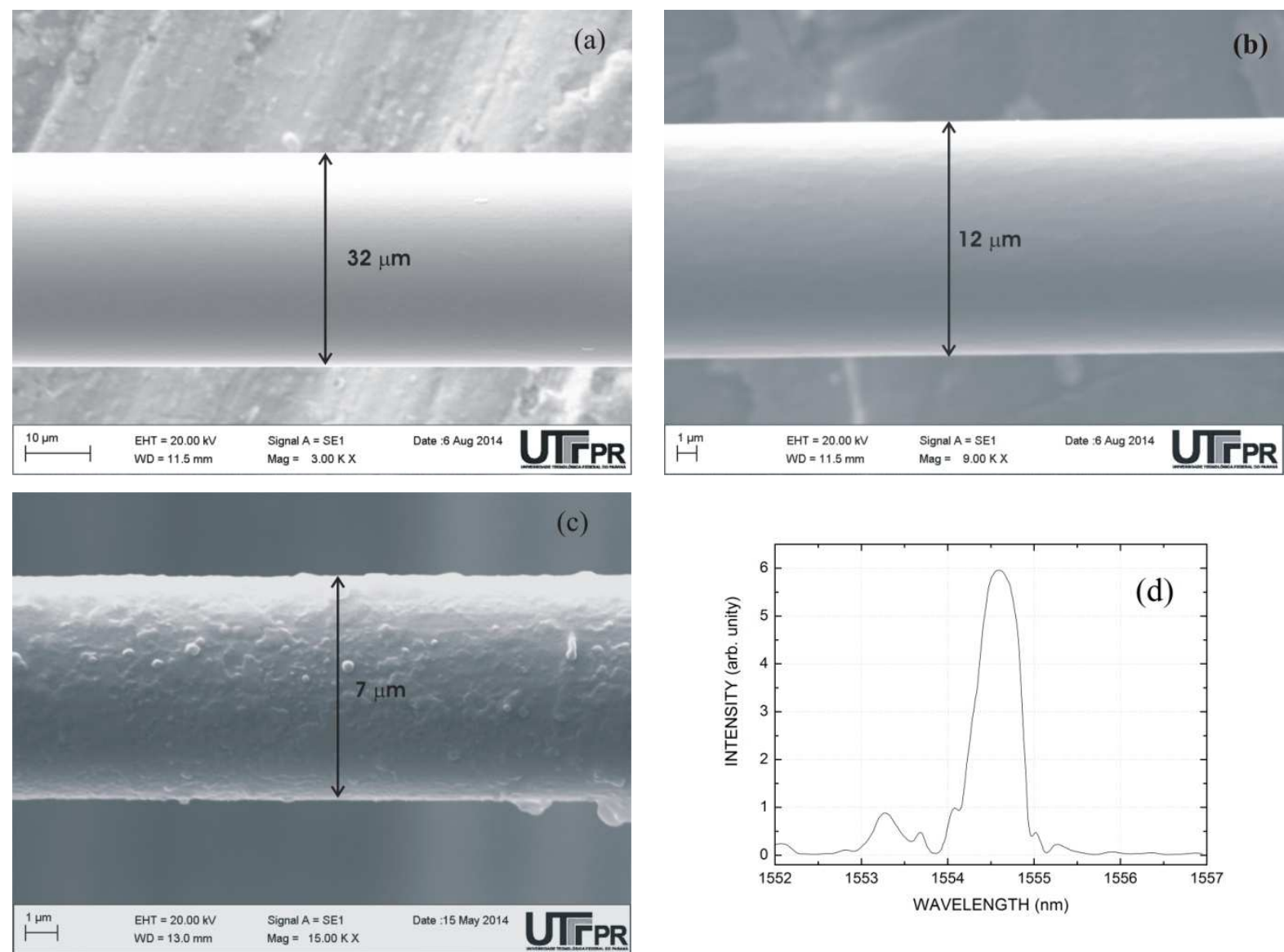

Fig. 1. SEM images of etched FBGs with diameter of: (a) $32 \mu \mathrm{m}$, (b) $12 \mu \mathrm{m}$ and (c) $7 \mu \mathrm{m}$; (d) Reflection spectrum of FBG with fiber diameter of $32 \mu \mathrm{m}$ in water.

Figure 2 shows refractive indexes of water-glycerin samples measured at $22.0{ }^{\circ} \mathrm{C}$ with the Abbe 
refractometer. Experimental data provide a linear response curve from 1.3328 (100\% water) to about $1.4656\left(100 \%\right.$ glycerin) with a slope of $(1.330 \pm 0.005) \times 10^{-4} \% \mathrm{v} / \mathrm{v}^{-1}$.

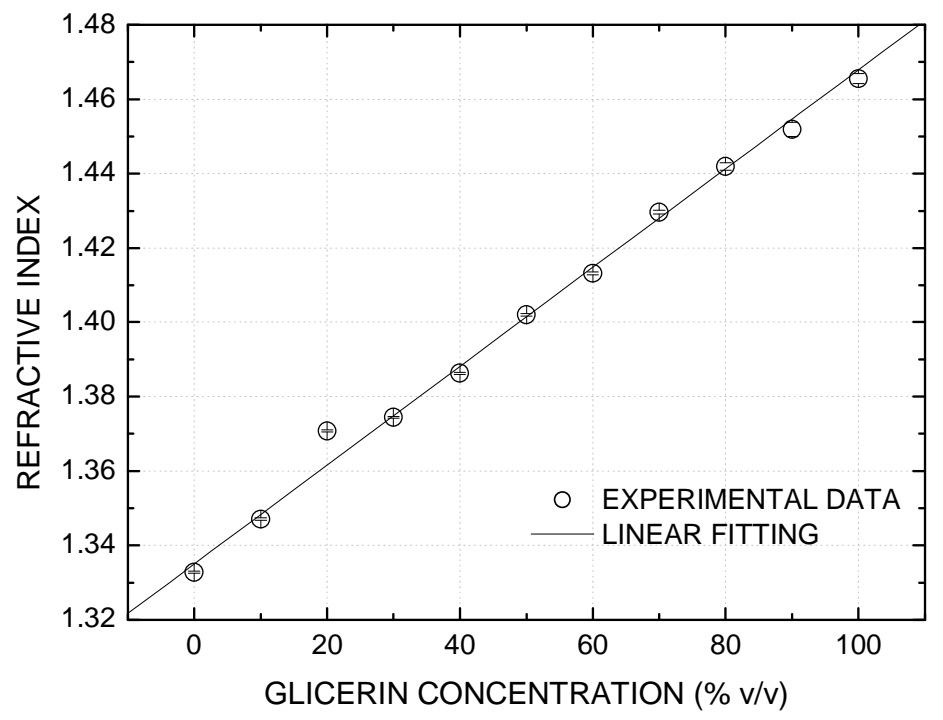

Fig. 2. Refractive index of water-glycerin samples at $22.0^{\circ} \mathrm{C}$.

Etched FBGs sensitivities to the external medium refractive index were obtained from the gratings responses to the water-glycerin samples. Response curves (left axis) and sensitivities (right axis) are presented in Figure 3 (a), (b) and (c). Solid curves depict the best fittings to the empirical equation (1):

$$
\lambda=a_{1}-\frac{a_{2}}{\left(a_{3}-n\right)}
$$

where $n$ is the external medium (water-glycerin samples) refractive index and $a_{1}, a_{2}$ and $a_{3}$ are the fitting parameters given in Table I.
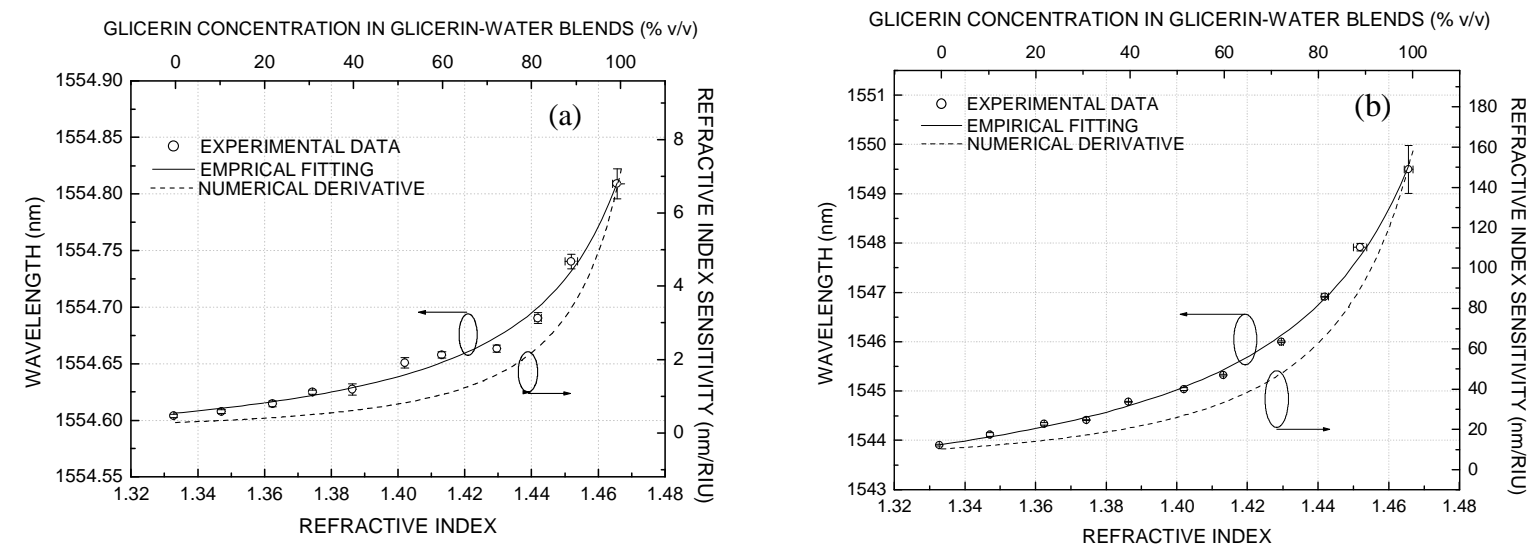


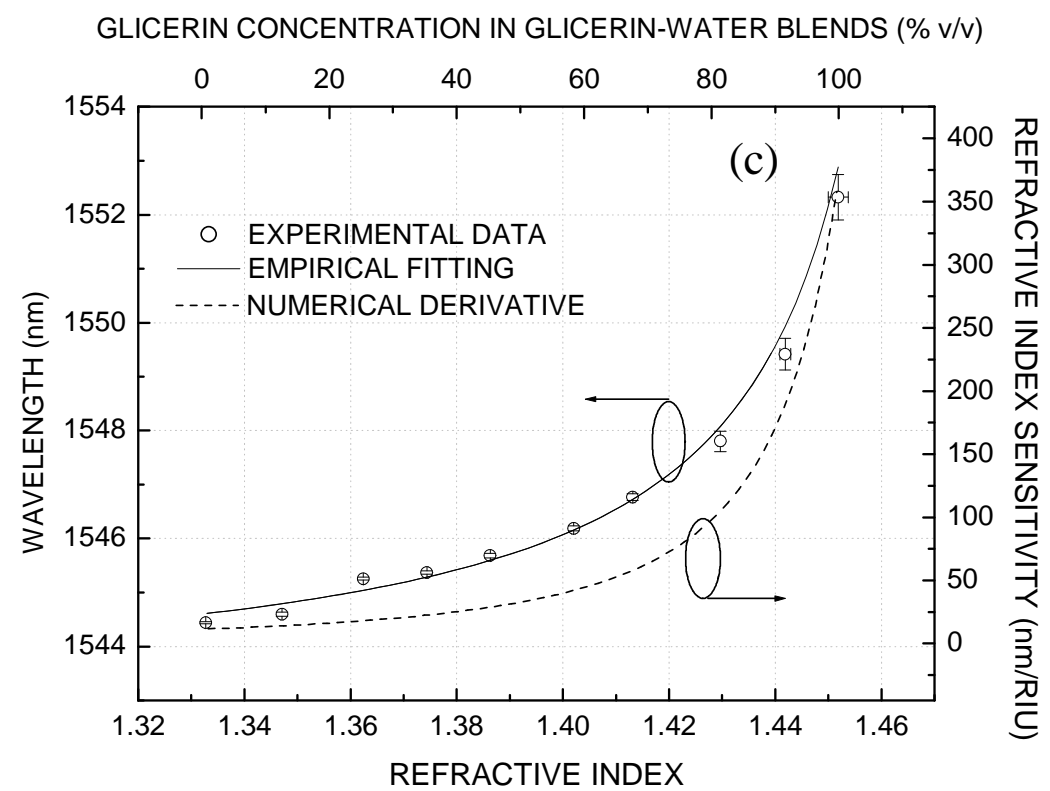

Fig. 3. FBG response curve (left) and refractive index sensitivity (right) as function of the external medium refractive index for fiber diameter of: (a) $32 \mu \mathrm{m}$, (b) $12 \mu \mathrm{m}$ and (c) $7 \mu \mathrm{m}$.

Dashed curves represent gratings sensitivities to the external refractive index, obtained by numerical derivative of the fitted response curves.

For the FBG with diameter of $7 \mu \mathrm{m}$, Figure 3(c), uncertainties in the Bragg wavelength position are larger for samples with glycerin concentration of $70 \%, 80 \%$ or $90 \%( \pm 0.18, \pm 0.29$ and \pm 0.42 respectively) than for the other concentrations. Such feature is noticed for FBG with diameter of 12 $\mu \mathrm{m}$, Figure 3 (b), just for concentrations close to $90 \%$ ( $\pm 0.49 \mathrm{~nm}$ uncertainty).

\begin{tabular}{|c|c|c|c|}
\hline Fiber diameter $(\mu \mathrm{m})$ & $a_{1}(\mathrm{~nm})$ & $a_{2}(\mathrm{~nm})$ & $a_{3}$ \\
\hline 32 & $1545.54 \pm 0.01$ & $-0.003 \pm 0.001$ & $1.5739 \pm 0.0368$ \\
\hline 12 & $1542.13 \pm 0.19$ & $-0.312 \pm 0.031$ & $1.5075 \pm 0.0035$ \\
\hline 7 & $1543.05 \pm 0.18$ & $-0.216 \pm 0.018$ & $1.4734 \pm 0.0016$ \\
\hline
\end{tabular}

When the refractive index of the external medium increases toward the fiber core one, both fiber guiding capability and transmitted power decrease accounting for large uncertainties. The degradation in the signal-to-noise ratio (SNR) becomes more restrictive for sensing purposes as the fiber radius decreases. Figure 4 shows the normalized power reflected by the FBG with diameter of $7 \mu \mathrm{m}$ relatively to the injected power as the refractive index of external medium increases. 


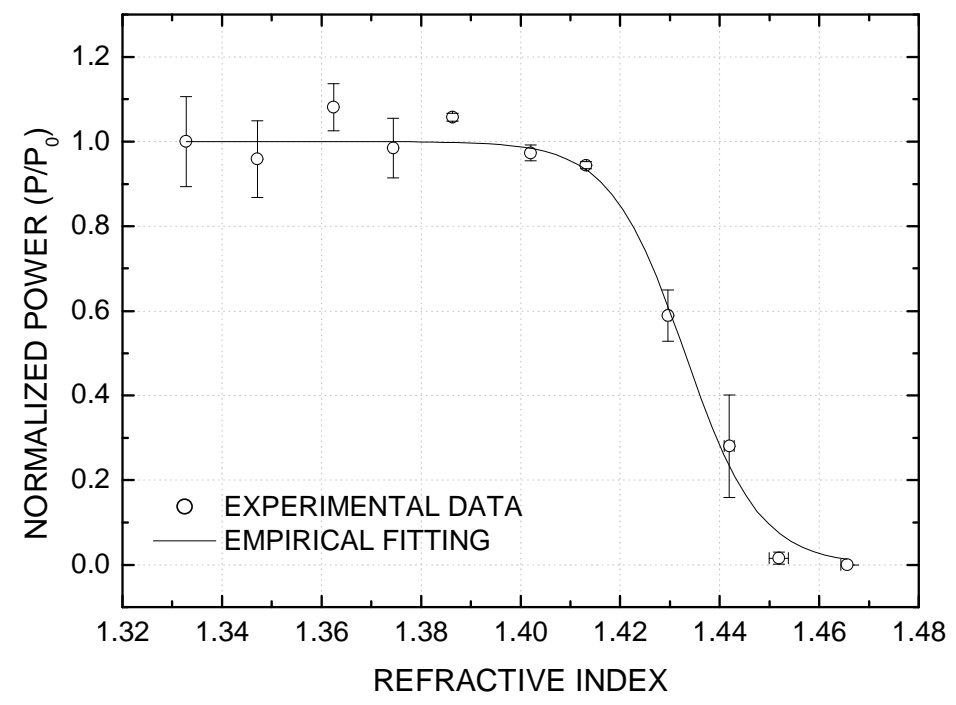

Fig. 4. reflected power for the FBG with $7 \mu \mathrm{m}$ of diameter as a function of the external medium refractive index.

Another feature that can be responsible for the degradation of the signal-to-noise ratio (SNR) when the glycerin concentration is close to $90 \%$ is the appearance of adjacent modes in the FBG reflection spectrum. This behavior can be observed by comparing spectra of figures 5 (a) and (b) obtained for the FBG with diameter of $7 \mu \mathrm{m}$ immersed in external media with refractive indexes of $1.3328(100 \%$ water) and 1.4729 (90\% glycerin), respectively. The same behavior was observed for the FBG with diameter of $12 \mu \mathrm{m}$.
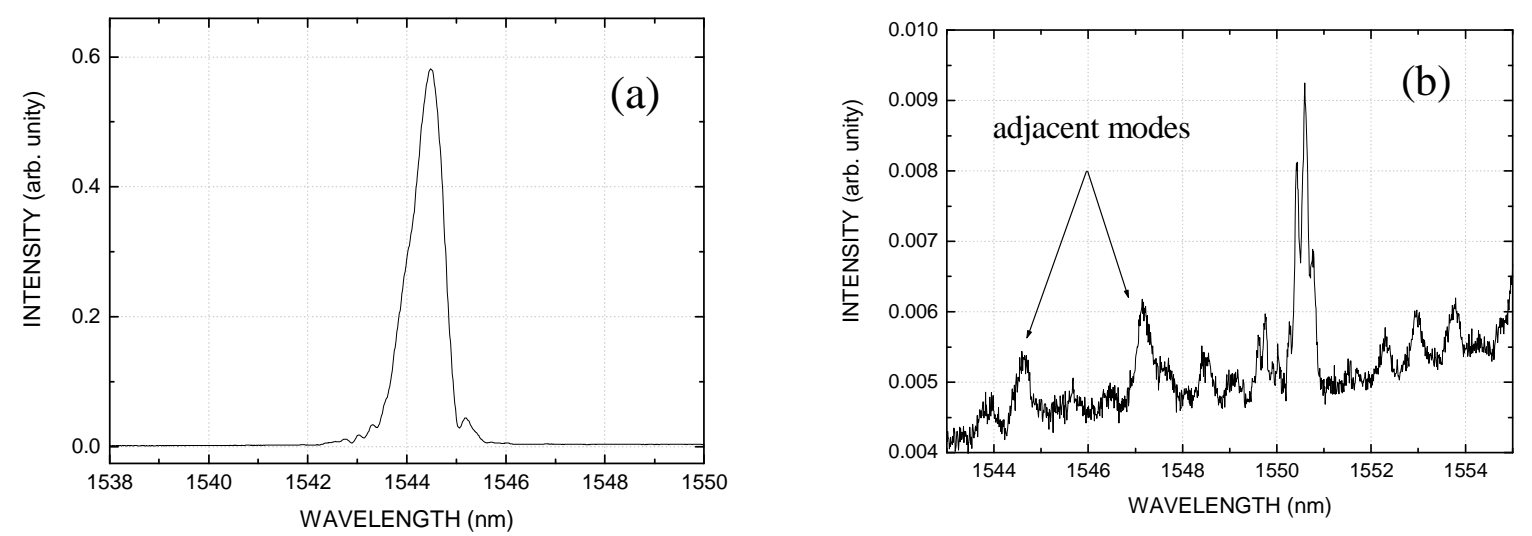

Fig. 5 Reflection spectra for FBG with diameter of $7 \mu \mathrm{m}$, when the external medium refractive index is (a) $1.3328(100 \%$ water) and (b) 1.4512 (90\% glycerin).

No signal degradation was observed for the FBG with diameter of $32 \mu \mathrm{m}$ within the whole refractive index dynamic range associated with water-glycerin blends. Such characteristic allows employing this FBG for sensing samples as soybean oil-biodiesel blends, which present high refractive indexes (typically above 1.4656), without the need for sample processing. 
Figure 6 shows the refractive indexes of oil-biodiesel blends at $22.0{ }^{\circ} \mathrm{C}$. Sample refractive index increases with the oil concentration in the blend from 1.4562 (100\% biodiesel) to 1.4729 (100\% oil) at a constant rate of $(1.690 \pm 0.020) \times 10^{-4}(\% \mathrm{v} / \mathrm{v})^{-1}$.

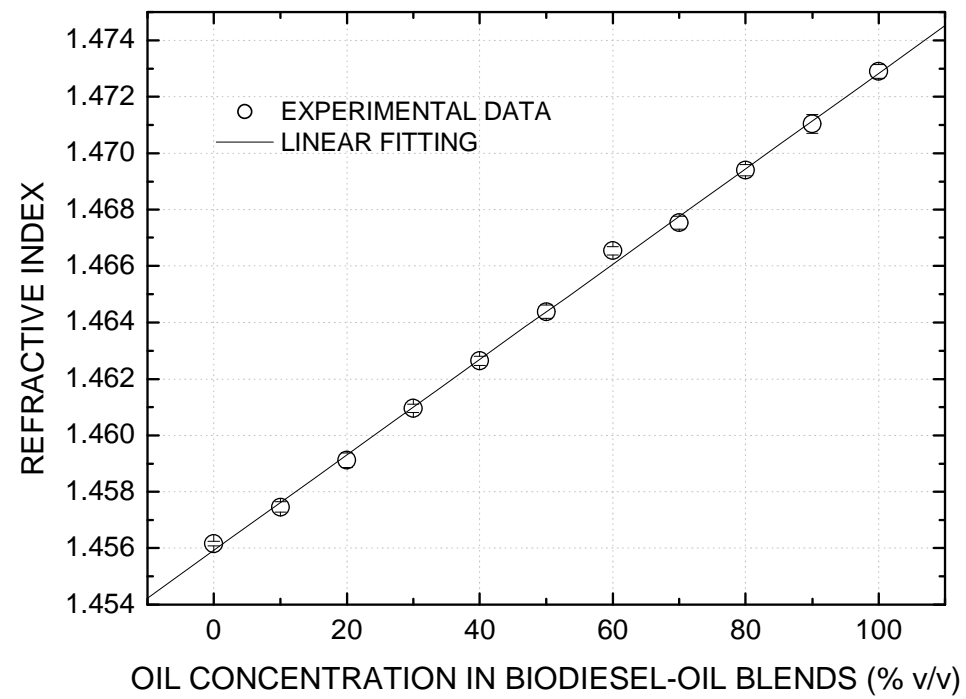

Fig. 6 Refractive indexes of oil-biodiesel blends at $22.0^{\circ} \mathrm{C}$.

The response of the FBG with diameter of $32 \mu \mathrm{m}$ for oil-biodiesel blends is presented in figure 7(a). Sensor calibration curve (solid curve) relates to a second order polynomial fitting. Sensor sensitivity curve obtained from the derivative of calibration curve (solid line) as well as the sensor resolution (dotted curve) obtained from the division of OSA wavelength stability by the sensitivity curve are shown in figure 7 (b).
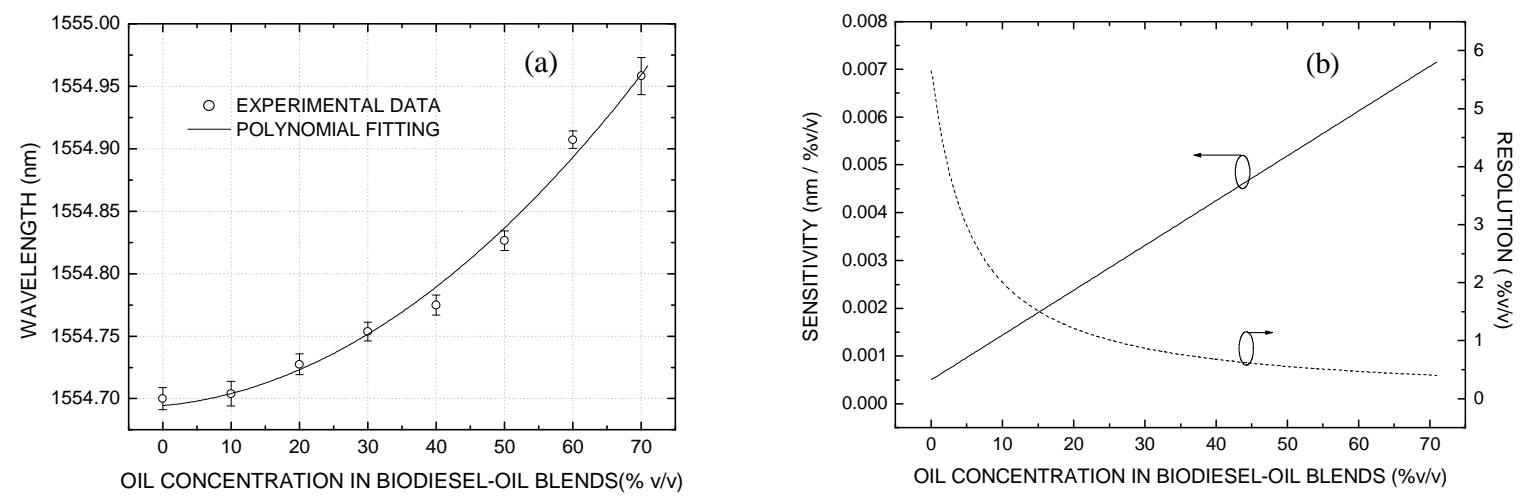

Fig. 7(a) Calibration curve of the sensor based on an FBG with diameter of $32 \mu \mathrm{m}$, and (b) sensor sensitivity (left axis) and resolution (right axis).

From the sensor resolution curve, it is inferred that the device is not able to determine oil concentrations smaller than $30 \% \mathrm{v} / \mathrm{v}$ with resolution less than $1 \% \mathrm{v} / \mathrm{v}$. Such characteristic makes the sensor not adequate to assess the biodiesel quality regarding the presence of residual oil in the final product. On the other hand, for oil concentrations above $30 \%$, oil concentration can be determined with sensor resolution better than $1 \% \mathrm{v} / \mathrm{v}$. As diesel refractive index (1.4701) is close to the oil 
(1.4729), biodiesel-diesel and biodiesel-oil blends show similar refractive indexes for equivalent constituent proportions. These features allow determining large amounts of oil in biodiesel and, markedly, suggest the use of the sensor in the conformity assessment of biodiesel-diesel fuel to be commercialized in Brazil. Metrological characteristics of the proposed sensor are presented in Table II [13].

\begin{tabular}{|c|c|}
\hline $\begin{array}{c}\text { Metrological Characteristic } \\
(\% \mathrm{v} / \mathrm{v})\end{array}$ & $\begin{array}{c}\text { Oil Concentration } \\
\mathbf{7 0 \%}\end{array}$ \\
\hline Resolution & 0.40 \\
\hline Reproducibility & 2.02 \\
\hline Conformity & 0.64 \\
\hline Combined Uncertainty & 2.15 \\
\hline
\end{tabular}

\section{CONCLUSIONS}

The results obtained in this work show that chemically etched FBG produced in multimode fiber presents high potential to be employed as sensor for highly refractive fuels. Lower diameter FBGs are more sensitive and suitable for high resolution sensors, but the degradation in the SNR, mainly caused by the strong attenuation in the guided optical signal, decreases the upper limit of the refractive index dynamic range. As a result, these devices are more adequate for quality assessment of biodiesel concerning to the presence of remaining vegetable oil in biodiesel.

On the other hand, higher diameters FBGs present lower sensitivity, despite being effective transducers with expanded upper limit in the refractive index dynamic range, only accessible nowadays by means of auxiliary techniques. Its use is more adequate for conformity analysis of diesel-biodiesel blends.

As the transducer was produced in a multimode-fiber, the cladding reduction by chemical etching did not impair its robustness. The sensor head was employed under laboratory conditions for three months without reduction of its mechanical strength.

\section{ACKNOWLEDGMENT}

The authors thank FINEP, CAPES, CNPq and Fundação Araucária (Brazilian Agencies) for scholarships and funding support. FBGs were fabricated at the Photo Refractive Devices Unit of Federal University of Technology - Paraná, associated laboratory of INCT Fotonicom.

\section{REFERENCES}

[1] L. A. H. Nogueira, B. Pikman, "Biodiesel: as novas perspectivas de sustentabilidade", ANP Informe conjuntura \& Informação, vol. 19, pp. 1-4, 2002.

[2] ANP Agência Nacional do Petróleo, Gás Natural e Biocombustíveis - Brasil, Anuário Estatístico Brasileiro do Petróleo, Gás Natural e Biocombustíveis, 2012.

[3] http://www2.camara.leg.br/legin/fed/lei/2014/lei-13033-24-setembro-2014-779372-publicacaooriginal-1450.

[4] L. L. Guarieiro, M. N. Ribeiro, A. C. Pinto, "Desenvolvimento de metodologias para a quantificação das misturas Biodiesel:Diesel por infravermelho", $3^{\circ}$ Congresso Brasileiro de P\&D em Petróleo e Gás, IBP0250_5, 2005. 
[5] R. C. M. Faria, M. J. C. Rezende, A. C. Pinto, "Quantificação das misturas Biodiesel:Diesel: Desenvolvimento, Validação e Aplicação de uma nova metodologia Empregando Cromatografia Gasosa-Espectrometria de Massas”, in $4^{o}$ Congresso Brasileiro de P\&D em Petróleo e Gás Natural, 8.4.0057, pp.1-10, 2007.

[6] F. P. Fagundes, A. S. Silva, S. R. O. Souto, R. B. Garcia, M. Costa, "Utilização de Técnicas Espectroscópicas na Determinação do Percentual do Biodiesel em Misturas Binárias com o Diesel”, in $4^{\circ}$ Congresso Brasileiro de P\&D em Petróleo e Gás Natural, 4.4.0413, pp.1-9, 2007.

[7] W.L. Xie and H.T. Li "Hydroxyl content and refractive index determinations on transesterified soybean oil", Journal of the American Oil Chemists' Society, vol. 83, pp. 869-872, 2006.

[8] R. Falate, K. Nike, P. R. C. Neto, E, Cação Jr., M Muller, H. J. Kalinowski, J. L. Fabris, "Alternative technique for biodiesel quality control using an optical fiber long-period grating sensor”, Química Nova, v. 30, p. 1677-1680, 2007.

[9] M. S. Kawano, B. R. Heidemann, T. K. M. Cardoso, G. R. C. Possetti, R. C. Kamikawachi, M. Muller, J. L. Fabris, "Tailoring fiber grating sensors for assessment of highly refractive fuels", Applied Optics, v. 51, p. 2015-2022, 2012.

[10] G. R. C. Possetti, R. C. Kamikawachi, M. Muller, J. L. Fabris, "Optical fiber sensor temperature coded for concentration measurement of oil-biodiesel blends", Optical Fiber Technology, v. 19, p. 543-548, 2013.

[11] G. Tsigaridas, D. Polyzos, A. Ioannou, M. Fakis, P. Persephonis, "Theoretical and experimental study of refractive index sensors basedon etched fiber Bragg gratings", Sensors and Actuators A, vol. 209, pp. 9-15, 2014.

[12] B. N. Shivananju, M. Renilkumar, G. R. Prashanth, S. Asokan, and M. M. Varma, "Detection Limit of Etched Fiber Bragg Grating Sensors”, Jounal of Lightwave Technology, vol. 31, pp. 2441-2447, 2013.

[13] G. R. C. Possetti, R. C Kamikawachi, M. Muller and J. L. Fabris, "Metrological evaluation of optical fiber gratingbased sensors: an approach towards the standardization", Journal of Lightwave Technology, vol. 30, pp. 1 - 11, 2011. 